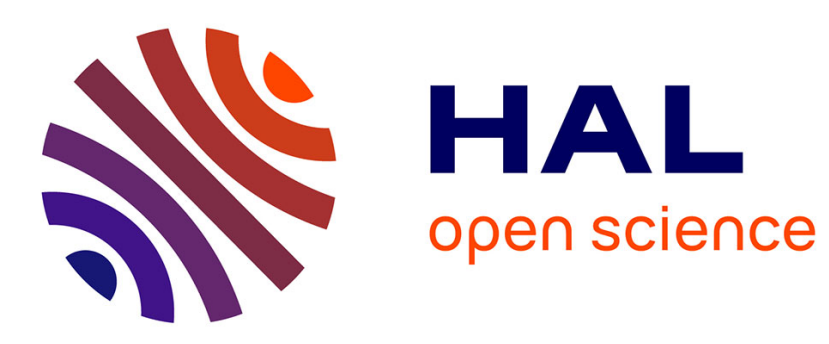

\title{
Species separation of a binary mixture in the presence of mixed convection
}

\author{
Ali Khouzam, Abdelkader Mojtabi, Marie-Catherine Charrier-Mojtabi, \\ Bafétigué Ouattara
}

\section{- To cite this version:}

Ali Khouzam, Abdelkader Mojtabi, Marie-Catherine Charrier-Mojtabi, Bafétigué Ouattara. Species separation of a binary mixture in the presence of mixed convection. International Journal of Thermal Sciences, 2013, vol. 73, pp.18-27. 10.1016/j.ijthermalsci.2013.05.012 . hal-00921009

\section{HAL Id: hal-00921009 \\ https://hal.science/hal-00921009}

Submitted on 19 Dec 2013

HAL is a multi-disciplinary open access archive for the deposit and dissemination of scientific research documents, whether they are published or not. The documents may come from teaching and research institutions in France or abroad, or from public or private research centers.
L'archive ouverte pluridisciplinaire HAL, est destinée au dépôt et à la diffusion de documents scientifiques de niveau recherche, publiés ou non, émanant des établissements d'enseignement et de recherche français ou étrangers, des laboratoires publics ou privés. 


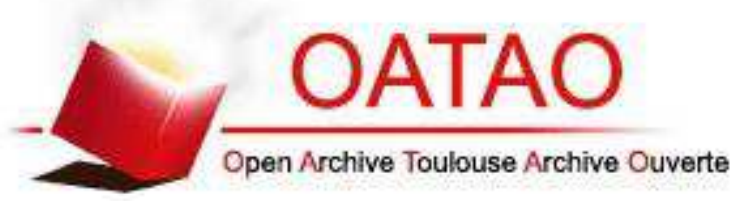

\section{Open Archive TOULOUSE Archive Ouverte (OATAO)}

OATAO is an open access repository that collects the work of Toulouse researchers and makes it freely available over the web where possible.

This is an author-deposited version published in : http://oatao.univ-toulouse.fr/ Eprints ID : 10558

To link to this article :

DOI:10.1016/j.ijthermalsci.2013.05.012

URL : http://dx.doi.org/10.1016/j.ijthermalsci.2013.05.012

\section{To cite this version :}

Khouzam, Ali and Mojtabi, Abdelkader and Charrier-Mojtabi, Marie-Catherine and Ouattara, Bafétigué Species separation of a binary mixture in the presence of mixed convection. (2013)

International Journal of Thermal Sciences, vol. 73 . pp. 18-27. ISSN 1290-0729

Any correspondance concerning this service should be sent to the repository administrator: staff-oatao@ listes-diff.inp-toulouse.fr 


\title{
Species separation of a binary mixture in the presence of mixed convection
}

\author{
Ali Khouzam ${ }^{\mathrm{a}, \mathrm{b}}$, Abdelkader Mojtabi $^{\mathrm{a}, \mathrm{b}, *}$, Marie-Catherine Charrier-Mojtabi $^{\mathrm{c}}$, \\ Bafétigué Ouattara ${ }^{\mathrm{a}, \mathrm{b}}$ \\ a Université de Toulouse, INPT, UPS, IMFT (Institut de Mécanique des Fluides de Toulouse), 1, Allée du Professeur, Allée Camille Soula, F-31400 Toulouse, \\ France \\ ${ }^{\mathrm{b}}$ CNRS, IMFT, F-31400 Toulouse, France \\ ${ }^{c}$ PHASE, EA 810, UFR PCA, Université Paul Sabatier, 118 route de Narbonne, 31062 Toulouse Cedex, France
}

Keywords:

Soret effect

Thermal diffusion

Mixed convection

Species separation

\begin{abstract}
A B S T R A C T
In this paper, an analytical and numerical study to determine the species separation process in a binary fluid mixture by decoupling the thermal gradient from the convective velocity was performed. The configuration considered is a horizontal rectangular cavity of large aspect ratio, filled with a binary fluid. A constant tangential velocity is applied to the upper horizontal wall. The two horizontal impermeable walls are maintained at different and uniform temperatures $T_{1}$ and $T_{2}$ with $\Delta T=T_{2}-T_{1}$. Species separation is governed by two control parameters, the temperature difference and the velocity of the upper plate $U \overrightarrow{e_{x}}$. The intensity of the thermodiffusion is controlled by the temperature gradient, while the velocity $U \overrightarrow{e_{x}}$ controls the convective flow. This problem depends on six dimensionless parameters, namely, the separation ratio $\psi$, the Lewis number $L e$, the Prandlt number $P r$, the aspect ratio of the cell $A$ and two control parameters: the thermal Rayleigh number, $R a$ and the Péclet number Pe. In this study, the separation (mass fraction difference between the two ends of the cell) is obtained analytically as a function of mass Péclet number $\left(P e_{m}=P e L e\right)$ and mass Rayleigh number $\left(R a_{m}=\psi R a L e\right)$. The optimal separation $m=\sqrt{42} / 15 \approx 0.432$ is obtained for $P e_{m}=\sqrt{42}$ and $R a_{m}=540$. The numerical results, obtained using the full governing equations, are in good agreement with the analytical results based on a parallel flow approximation.
\end{abstract}

\section{Introduction}

A temperature gradient applied to a binary fluid mixture induces a mass fraction gradient: this phenomenon, called thermodiffusion, is also known as the Ludwig-Soret effect or the Soret effect. Under the gravity field, the coupling between convection and thermodiffusion, called thermogravitational diffusion, may lead to species separation. In 1938, Clusius and Dickel [1] successfully carried out the separation of gas mixtures in a vertical cavity heated from the side, usually called a thermogravitational column (TGC). They observed a significant separation of the components of the gas, and suggested that the technique could be used for component and isotope separation. In 1939, Furry et al. [2]

\footnotetext{
* Corresponding author. Université de Toulouse, INPT, UPS, IMFT (Institut de Mécanique des Fluides de Toulouse), 1, Allée du Professeur, Allée Camille Soula, F31400 Toulouse, France.

E-mail address: mojtabi@cict.fr (A. Mojtabi).
}

developed a fundamental theory to interpret the experimental process of isotope separation in a thermogravitational column (FJO theory). However, in their study, the authors did not take into account the influence of the concentration gradient on the density gradient, which is referred to as the "forgotten effect". Afterwards, many works were devoted to justifying and extending the results of the FJO theory to the case of binary liquids.

Other studies were carried out to improve the experimental devices and increase the separation. Lorenz and Emery [3] introduced a porous medium in the TGC columns. Bou-Ali et al. [4] observed that a binary fluid, with a negative Soret coefficient, in a thermogravitational column, could remain stable if the Grashof number was sufficiently high. The authors analyzed the stability of the steady-state adverse density gradient obtained along the layer. A three-dimensional numerical study of Soret-driven convection in a cubic cell filled with a binary mixture of water (90\%) and isopropanol (10\%) was performed by Shevtsova et al. [5]. The instabilities occurring in this binary fluid with negative Soret coefficient for a cubic cell heated from above was analyzed [6]. 


\begin{tabular}{|c|c|c|c|}
\hline \multicolumn{2}{|c|}{ Nomenclature } & $S$ & species separation $(S=m A)$ \\
\hline$A$ & aspect ratio of the cavity & $t$ & dimensionless time \\
\hline$a$ & thermal diffusivity, $\left[\mathrm{m}^{2} \mathrm{~s}^{-1}\right]$ & $T$ & dimensionless temperature \\
\hline C & dimensionless mass fraction $\left(C^{*}-C_{0}^{*}\right) / \Delta C^{*}$ & $T_{0}$ & reference temperature \\
\hline$C_{0}$ & initial mass fraction & $(u, v)$ & dimensionless velocity components in $(x, z)$ directions \\
\hline$D$ & mass diffusion coefficient & & \\
\hline$D_{\mathrm{T}}$ & thermodiffusion coefficient $\left[\mathrm{m}^{2} \mathrm{~s}^{-1} \mathrm{~K}^{-1}\right]$ & \multicolumn{2}{|c|}{ Greek symbols } \\
\hline$g$ & gravitational acceleration $\left[\mathrm{ms}^{-2}\right]$ & $\beta_{\mathrm{c}}$ & solutal expansion coefficient \\
\hline$H$ & height of the enclosure [m] & $\beta_{\mathrm{T}}$ & thermal expansion coefficient $[1 / \mathrm{K}]$ \\
\hline$L$ & length of the enclosure [m] & $\lambda$ & thermal conductivity $\left[\mathrm{Wm}^{-1} \mathrm{~K}^{-1}\right]$ \\
\hline$m$ & mass fraction gradient & $\mu$ & dynamic viscosity [Pa s] \\
\hline Le & Lewis number & $\nu$ & kinematic viscosity of the mixture, $\left[\mathrm{m}^{2} \mathrm{~s}^{-1}\right]$ \\
\hline$P$ & pressure [Pa] & $\rho$ & density of the mixture, $\left[\mathrm{kgm}^{-3}\right]$ \\
\hline $\mathrm{Pe}$ & Péclet number & $\psi$ & separation ratio \\
\hline$P e_{m}$ & mass Péclet number & & \\
\hline $\operatorname{Pr}$ & Prandtl number & \multicolumn{2}{|c|}{ Superscript } \\
\hline$R a$ & Rayleigh number & $*$ & for dimensional variables \\
\hline$R a_{m}$ & mass Rayleigh number & 0 & refers to a reference state \\
\hline
\end{tabular}

In order to increase the separation, Platten et al. [7] used an inclined cavity, heated from the top. Elhajjar et al. [8] suggested a new method to obtain species separation in a binary fluid mixture. They used a horizontal cavity heated from above and subjected to a constant horizontal temperature gradient on the two horizontal walls to improve the separation process depending on two control parameters. They obtained significant separation (10\%) with realistic values of the thickness (about $2 \mathrm{~mm}$ ), while very low thicknesses $(0.2 \mathrm{~mm})$ were required in vertical cells to obtain separation with the same order of magnitude. Charrier-Mojtabi et al. [9] developed a linear stability analysis of the unicellular flow that appears at the onset of convection in a horizontal porous cavity saturated by a binary fluid and heated from below. The authors showed that, if the separation ratio $\psi$ was positive and greater than a particular value, $\psi_{\text {mono }}$, it was possible to separate the species of the binary fluid mixture between the two ends of the cell.

Elhajjar et al. [10] showed that the Rayleigh number leading to the optimum separation in a horizontal cell was larger than the one obtained in a vertical cell (TGC), which allowed separation to be performed in a cell of greater thickness. The existence of multiple solutions and the influence of the Soret effect on the convection in a horizontal porous layer under crossed temperature and concentration gradients were discussed by Bennacer et al. [11]. Zebib and Bou-Ali [12] performed a linear stability analysis of a binary mixture buoyant return flow in a tilted, differentially heated, infinite layer using asymptotic long-wave analysis and pseudospectral Chebyshev numerical solutions. Elhajjar et al. [13] studied the influence of vertical high-frequency and small-amplitude vibrations on the stability of the unicellular flow in a shallow horizontal porous layer saturated by a binary fluid and heated from below. Alloui et al. [14] used the Darcy model with the Boussinesq approximation to study natural convection in a porous medium saturated by a binary fluid. It was found that both unicellular and bicellular symmetrical circulations were possible for a centrally located heated element. Elhajjar et al. [15] presented a theoretical and numerical study of species separation in an inclined porous cavity.

In this paper, a study of the species separation in a binary fluid mixture is presented using a new geometrical configuration. The binary fluid mixture is confined in a shallow horizontal rectangular cavity heated either from above or from below. The two horizontal impermeable walls are maintained at uniform temperatures $T_{1}$ and $T_{2}$. The upper horizontal wall moves with a constant velocity $U \overrightarrow{e_{x}}$.
The paper is organized as follows. Section 2 provides the mathematical formulation of the problem. We present the analytical solution obtained in Section 3. In Section 4 we present the numerical method, in Section 5 we discuss the analytical results. The velocity profile is analyzed in Section 6 . We draw some conclusions in Section 7.

\section{Mathematical formulation}

\subsection{Model and the basic equations}

We consider a horizontal rectangular cavity of large aspect ratio $A=L / H$ (cf Fig. 1 ), where $H$ is the height of the cavity along the $z$-axis and $L$ is the length along the $x$-axis. The cavity is filled with a binary fluid mixture of density $\rho^{*}$ and dynamic viscosity $\mu$. The two walls $x^{*}=0$ and $x=L$ are adiabatic and impermeable. The two other walls $z^{*}=0$ and $z^{*}=H$ are kept at uniform temperatures, $T_{1}$ for $z^{*}=H$ and $T_{2}$ for $z^{*}=0$, with $T_{1}<T_{2}$ or $T_{1}>T_{2}$. The binary mixture is assumed to be Newtonian and satisfy the Boussinesq approximation. Thus, the density of the fluid mixture, $\rho^{*}$, is a function of the local temperature, $T^{*}$, and the local mass fraction, $C^{*}$. We can use a linear law to represent $\rho^{*}$, which is completely reasonable for small temperature and mass fraction differences:

$\rho^{*}=\rho_{0}^{*}\left[1-\beta_{\mathrm{T}}\left(T^{*}-T_{0}^{*}\right)-\beta_{\mathrm{C}}\left(C^{*}-C_{0}^{*}\right)\right]$

The thermal and mass expansion coefficients $\left(\beta_{\mathrm{T}}, \beta_{\mathrm{C}}\right)$ are defined as follows:

$$
\beta_{\mathrm{T}}=-\frac{1}{\rho_{0}}\left(\frac{\partial \rho^{*}}{\partial T^{*}}\right)_{C^{*}}, \quad \beta_{\mathrm{C}}=-\frac{1}{\rho_{0}}\left(\frac{\partial \rho^{*}}{\partial C^{*}}\right)_{T^{*}}
$$

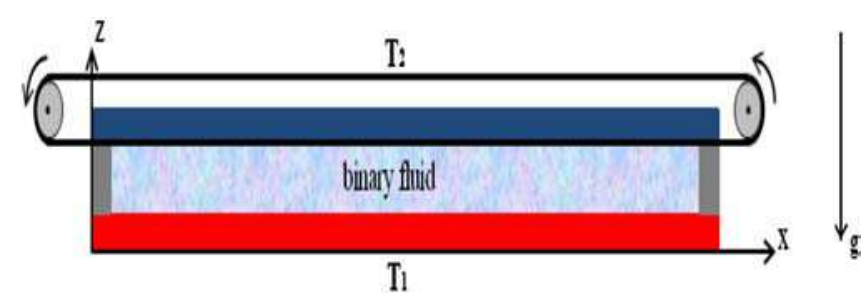

Fig. 1. Geometry of the physical problem. 
The heat and the mass fraction flux in the binary mixture are coupled due to the Soret effect and both contribute to the density gradient. The buoyancy force $\rho^{*} \vec{g},\left(\vec{g}=-g \overrightarrow{e_{z}}\right)$, is thus influenced by the Soret effect. Under these conditions, the mathematical model governing this problem, which includes the conservation equations (mass, momentum, energy and chemical species), are written respectively as follows:

$\nabla \cdot \vec{V}^{*}=0$

$\rho_{0}^{*}\left(\frac{\partial \overrightarrow{V^{*}}}{\partial t^{*}}+\overrightarrow{V^{*}} \cdot \nabla \overrightarrow{V^{*}}\right)=-\nabla P^{*}+\rho_{0}^{*}\left[1-\beta_{\mathrm{T}}\left(T^{*}-T_{0}^{*}\right)\right.$

$$
\left.-\beta_{C}\left(C^{*}-C_{0}^{*}\right)\right] \vec{g}+\mu \nabla^{2} \overrightarrow{V^{*}}
$$

$\frac{\partial T^{*}}{\partial t^{*}}+\overrightarrow{V^{*}} \cdot \nabla T^{*}=a \nabla^{2} T^{*}$

$\frac{\partial C^{*}}{\partial t^{*}}+\overrightarrow{V^{*}} \cdot \nabla C^{*}=\nabla \cdot\left(D \nabla C^{*}+D_{\mathrm{T}} C^{*}\left(1-C^{*}\right) \nabla T^{*}\right)$

where $D$ and $D_{\mathrm{T}}$ are respectively the mass diffusion and the thermodiffusion coefficients. Typically, in Soret-driven convection, if the mass fraction is small, $C^{*}\left(1-C^{*}\right)$ can be replaced by $C_{0}^{*}\left(1-C_{0}^{*}\right), C_{0}^{*}$ being the mass fraction in the initial state and Eq. (5) leads to:

$\frac{\partial C^{*}}{\partial t^{*}}+\overrightarrow{V^{*}} \cdot \nabla C^{*}=D \nabla^{2} C^{*}+D_{\mathrm{T}} C_{0}^{*}\left(1-C_{0}^{*}\right) \nabla^{2} T^{*}$

\subsection{Boundary conditions}

The associated boundary conditions include a constant velocity applied at the upper wall, no-slip conditions for the velocity at the other rigid walls, distinct constant temperatures on the top and bottom walls. Vertical walls are impermeable and thermally insulated. Accordingly, the associated boundary conditions are defined as follows:

$\begin{cases}\overrightarrow{V^{*}}\left(x^{*},\right. & \left.z^{*}=H\right)=U \overrightarrow{e_{x}} \\ \overrightarrow{V^{*}}\left(x^{*},\right. & \left.z^{*}=0\right)=\overrightarrow{V^{*}}\left(x^{*}=(0, L), z^{*}\right)=0\end{cases}$

$\left\{T^{*}\left(x^{*}, \quad z^{*}=H\right)=T_{1}\right.$

$\left\{T^{*}\left(x^{*}, \quad z^{*}=0\right)=T_{2}\right.$

$\frac{\partial C^{*}\left(x^{*}, z^{*}\right)}{\partial z^{*}}-C_{0}^{*}\left(1-C_{0}^{*}\right) S_{\mathrm{T}} \frac{\partial T^{*}\left(x^{*}, z^{*}\right)}{\partial z^{*}}=0$ for $z^{*}=0, H$

$$
\forall x^{*} \in[0, L]
$$

$\frac{\partial C^{*}\left(x^{*}, z^{*}\right)}{\partial x^{*}}=\frac{\partial T^{*}\left(x^{*}, z^{*}\right)}{\partial x^{*}}=0$ for $x^{*}=0$ and $x^{*}=L$

$$
\forall z^{*} \in[0, H]
$$

where the Soret coefficient, $S_{\mathrm{T}}$, is defined as: $S_{\mathrm{T}}=D_{\mathrm{T}} / D$.

\subsection{Dimensionless equations}

The reference scales are: $H$ for length, $H^{2} / a$ for time, $\rho_{0} a^{2} / H^{2}$ for pressure, and $a / H$ for velocity. The dimensionless temperature and mass fraction are given by:
$T=\left(T^{*}-T_{0}^{*}\right) / \Delta T^{*}, \quad C=\left(C^{*}-C_{0}^{*}\right) / \Delta C^{*}$

where $\Delta T^{*}=T_{2}-T_{1}, \quad \Delta C^{*}=\Delta T^{*} C_{0}^{*}\left(1-C_{0}^{*}\right) D_{\mathrm{T}} / D$ and $T_{0}^{*}=T_{1}, C_{0}^{*}=C_{0}$ (since $C_{0}$ is the dimensionless mass fraction).

Using the dimensionless variables in Eqs. (2)-(5), we obtain the dimensionless governing equations:

$\nabla \cdot \vec{V}=0$

$\frac{\partial \vec{V}}{\partial t}+\vec{V} \cdot \nabla \vec{V}=-\nabla P+\operatorname{Ra} \operatorname{Pr}[T-\psi C] \vec{e}_{z}+\operatorname{Pr} \nabla^{2} \vec{V}$

$\frac{\partial T}{\partial t}+\vec{V} \cdot \nabla T=\nabla^{2} T$

$\frac{\partial C}{\partial t}+\vec{V} \cdot \nabla C=\frac{1}{L e}\left(\nabla^{2} C+\nabla^{2} T\right)$

The problem considered depends on six dimensionless parameters:

The Rayleigh number $R a=g \beta_{\mathrm{T}} \Delta T H^{3} / v a$, the Prandtl number, $\operatorname{Pr}=v / a$, the Lewis number, $L e=a / D$, the Péclet number, $P e=\operatorname{Pr} R e$, where $R e=U L / v$, (Reynolds number), the separation ratio, $\psi=-\beta_{C} D_{T} C_{0}\left(1-C_{0}\right) / \beta_{C} D$ and the aspect ratio $A=L / H R a>0$ if the cell is heated from below, and $R a<0$ if the cell is heated from above. Moreover, a positive separation ratio is considered, which implies that, due to thermodiffusion, the denser component of the mixture migrates toward the cold wall.

The associated dimensionless boundary conditions are:

$$
\begin{aligned}
& \vec{V}(x, z=0)=\vec{V}(x=(0, A), z)=0 \text { and } \\
& \vec{V}(x, z=1)=P e \overrightarrow{e_{x}}, \quad \forall x \in[0, A] \\
& T(x, z=0)=1 \text { and } \quad T(x, z=1)=0, \quad \forall x \in[0, A] \\
& \frac{\partial C(x, z)}{\partial z}+\frac{\partial T(x, z)}{\partial z}=0 \quad \text { for } z=0 \text { and } z=1, \quad \forall x \in[0, A]
\end{aligned}
$$

$\frac{\partial C(x, z)}{\partial x}=\frac{\partial T(x, z)}{\partial x}=0$ for $x=0$ and $x=A, \quad \forall z \in[0,1]$

\section{Analytical solution}

In the case of a shallow cavity $(A \gg 1)$ in order to solve the problem analytically, the parallel flow approximation (Bennacer et al. [11], Elhajjar et al. [15]) is considered. The streamlines are assumed to be parallel to the horizontal walls except for the vicinity of the vertical walls. In this case, the vertical component of velocity can be neglected:

$\left.\vec{V}(x, z)=u(z) \overrightarrow{e_{x}}, \quad \forall x \in\right] 0, A[$

This assumption implies steady-state and the inertia term $(\vec{V} \cdot \nabla) \vec{V}$ in Eq. (12) is equal to zero. The temperature and mass fraction profiles are written as the sum of two terms: the first one defining the linear longitudinal variation and the second one giving the transverse distribution:

$T(x, z)=b x+f(z)$

$C(x, z)=m x+g(z)$ 
where $b$ and $m$ are respectively the unknown constant temperature gradient and mass fraction gradient in the $x$ direction. $b=0$ due to the constant temperatures imposed on the horizontal walls.

Once we eliminate the pressure in the Navier-Stokes equation (19)-(21), the following system of equations is obtained for the steady state:

$\frac{\partial^{3} u(z)}{\partial z^{3}}-R a \frac{\partial}{\partial x}(T-\psi C)=0$

$\nabla^{2} T=0$

$m$ Le $u(z)-\frac{\partial^{2} C}{\partial z^{2}}=0$

Since the boundary conditions on the vertical walls are not taken into account for the velocity, additional conditions are needed to solve the system of Eqs. (22)-(24) which are:

- The mass flow rate through any cross section perpendicular to the $x$-axis is equal to zero,

- The mass of the denser component is conserved across the whole cell:

$$
\begin{aligned}
& \int_{0}^{1} u \mathrm{~d} z=0 \quad \forall x \in[0, A] \\
& \int_{0}^{1} \int_{0}^{A} C \mathrm{~d} z \mathrm{~d} x=0
\end{aligned}
$$

Applying these conditions and the boundary conditions (15)(18), the velocity, temperature and mass fraction fields are given by the following expressions:

$u=\left(-\frac{1}{6} z^{3}+\frac{1}{4} z^{2}-\frac{1}{12} z\right) R a \psi m+\left(3 z^{2}-2 z\right) P e$

$T=1-z$

$$
\begin{aligned}
C= & m x-\left(\frac{1}{120} z^{5}-\frac{1}{48} z^{4}+\frac{1}{72} z^{3}+\frac{1}{1440}\right) R a \psi m^{2} L e+z \\
& -\frac{1+m A}{2}+\left(\frac{1}{4} z^{4}-\frac{1}{3} z^{3}+\frac{1}{30}\right) m L e \text { Pe }
\end{aligned}
$$

The velocity presents a cubic profile, which is required to allow species separation between the two ends of the cell.

\section{Numerical method}

Unsteady numerical simulations were carried out in order to corroborate the analytical results. For this purpose, the numerical solutions of the full governing equations (11)-(14) with the associated boundary conditions (15)-(18), were obtained using a finite element method (Comsol Multiphysics). The initial conditions considered were:

$$
\begin{aligned}
& T(x, z, t=0)=\left(T_{1}-T_{2}\right) / 2 \Delta T^{*}=0.5 \\
& U(x, z, t=0)=P e \text { and } C(x, z, t=0)=\left(C^{*}-C_{0}\right) / \Delta C^{*}=0 .
\end{aligned}
$$

The selected mesh should only be viewed as a compromise between the convergence and solver memory requirements (UMFPACK direct solver or PARDISO solver were used in our simulations). A 4000-element quadratic mesh (69986 degrees of freedom), which is more convenient for our rectangular cell problem, was used. As the analytical solution is valid for large aspect ratios, $A \geq 10$ was used for all numerical simulations. The computations performed for $A=10$ and $A=20$ led to the same results.

\section{Determination of the mass fraction gradient $\mathrm{m}$ along the $\boldsymbol{x}$ axis}

To determine the mass fraction gradient, $m$ along the $x$ axis, we use the fact that the mass flow rate of the component of mass fraction specie $C$ through any vertical section is equal zero:

$\int_{0}^{1}\left(u C-\frac{1}{L e}\left(\frac{\partial C}{\partial x}+\frac{\partial T}{\partial x}\right)\right) \mathrm{d} z=0, \quad \forall x \in[0, A]$

The latter assumption leads to the following cubic equation giving $m$ as a function of the dimensionless parameters: Pe, Ra, Le and $\psi$.

$$
\frac{L e^{2} R a^{2} \psi^{2}}{362,880} m^{3}+\frac{L e^{2} R a \psi P e}{3360} m^{2}+\left(1+\frac{L e^{2} P e^{2}}{105}-\frac{L e R a \psi}{720}\right) m-\frac{L e P e}{12}=0
$$

Eq. (30) depends only on the group of the two dimensionless parameters: (PeLe) and ( $\psi$ RaLe). These two dimensionless parameters have the following form:

PeLe $=U H / D=P e_{m}$ where $P e_{m}$ is the corresponding mass Péclet number, and $\psi R a L e=C_{0}\left(1-C_{0}\right) S_{T} g \beta_{C} \Delta T H^{3} / v D$. Considering the mass fraction difference resulting from pure Soret separation, we deduced that:

$\psi R a$ Le $=g \beta_{C} \Delta H^{3} / v D=R a_{m}$

where $R a_{m}$ is the mass Rayleigh number. $P e_{m}$ and $R a_{m}$ can either be positive or negative depending respectively on the sign of $U$ and $\psi$. With this new formulation of dimensionless numbers Eq. (30) takes the following form:

$\frac{R a_{m}^{2}}{362,880} m^{3}+\frac{R a_{m} P e_{m}}{3360} m^{2}+\left(1+\frac{P e_{m}^{2}}{105}-\frac{R a_{m}}{720}\right) m-\frac{P e_{m}}{12}=0$

\subsection{Determination of $m$ for $P e=0$}

For $P e=0$ (i.e. no velocity is applied at the upper wall), Eq. (31) admits three real roots:

$m=0$ and $m= \pm 6 \frac{\sqrt{-10,080+14 R a \psi L e}}{\text { Ra }}$

For $R a \geq 720 / R a \psi$ Le, the two nonzero roots are real and correspond to counter-clockwise unicellular convective flows. Knobloch et al. [16], obtained an analytically similar result: $\mathrm{Ra}_{\mathrm{uni}}=$ $720 / R a \psi$ Le when they analyzed the linear stability of the equilibrium double-diffusive solution in a binary fluid mixture $R a_{\text {uni }}$ corresponds to the critical Rayleigh number for the onset of supercritical double-diffusive convection, characterized by a transition from the quiescent double-diffusive state to unicellular double-diffusive convection in horizontal cell.

This result is obtained for $\psi>\psi_{\mathrm{uni}}=1 /[(34 / 131) L e-1]$. In saturated porous cell Charrier et al. [9] obtained similar result: $R a_{\text {uni }}=12 /$ Le $\psi$ and $\psi_{\text {uni }}=1 /[(40 L e / 51)-1]$. For $0<\psi<\psi$ uni, the onset of convection is associated with multi-cellular flow. 
Eq. (30) indicates that the value of the mass fraction gradient $m$ depends only on the $R a \psi L e$ for $P e=0$. The optimal value of the mass fraction gradient is found to be $m=\sqrt{70} / 20 \approx 0.418$, which occurs for $R a=1440 / \psi$ Le. This optimal Rayleigh number is equal to $R a=2 R a_{\text {uni. }}$. However, the unicellular flow can be unstable at $R a=2 R a_{\mathrm{uni}}$, therefore, stability analysis is needed to determine the range of $R a$ values, where unicellular flow can occur.

For $\psi>\psi_{\text {uni }}$ species separation between the two ends of the cell is only possible when the layer is heated from below $(R a>0)$. In fact, due to thermodiffusion, the denser particle moves toward the cold wall, inducing a positive vertical mass fraction gradient and leading to a unicellular flow. For $\psi<0$, the separation is only
The representation of the surface defined implicitly by $G\left(m, P e_{m}\right.$, $\left.R a_{m}\right)=0$ associated to Eq. (31), for $P e_{m}>0$ is shown in Fig. 4

It can be seen in Fig. 4 that, for the dimensionless parameter range considered, the equation has only a single real root with two complex conjugate roots or three real roots, two of which are opposite.

The positive or negative optimum values can be obtained respectively for $P e_{m}>0$ and $P e_{m}<0$. It can be observed, in Fig. 4, that the maximum value of the mass fraction gradient is $m_{\max } \approx 0.432$. This maximum was obtained in the case with one real solution and for $P e_{m}>0$. The optimum value of $P e_{m}$ is then given by:

$P e_{m, \text { opt }}= \pm \frac{\sqrt{-207,900-105 R a_{m}+70 \sqrt{6 R a_{m}-3240 R a_{m}+18,662,400}}}{30}$

possible when the layer is heated from above $(R a<0)$ In this case the denser particle moves toward the hot wall, inducing a positive vertical mass fraction gradient and leading to an unstable state.

Fig. 2 shows the critical and optimal Rayleigh number versus the separation ratio for $L e=100$. The solid line represents the critical Rayleigh number. The dashed line represents the optimal Rayleigh number for which maximal separation is obtained. The hatched zone of Fig. 2 represents the regions where separation is not possible.

\subsection{Analytical determination of $m$ in general case $\left(P e_{m} \neq 0\right.$ and $R a_{m} \neq 0$ )}

The cubic equation (31) with real coefficients admits three roots that depend on sign of the discriminant $\Delta$. If $\Delta>0$, the three roots are real and distinct and in the case of a negative discriminant, the equation has one real root and two complex conjugate roots Finally, for $\Delta=0$, the equation has a multiple root and all its roots are real. The discriminant $\Delta$ of Eq. (31) was obtained using Maple algebra code. Its expression, function of $R a_{m}$ and $P e_{m}$, is given as $\Delta=F\left(R a_{m}, P e_{m}\right)$ with $F$ equal to:

$$
\begin{aligned}
F=R a_{m}^{2}[ & 343 R a_{m}^{3}-\left(1764 P e_{m}^{2}+740,880\right) R a_{m}^{2} \\
& -\left(12,852 P e_{m}^{4}+6,985,440 P e_{m}^{2}-533,433,600\right) R a_{m} \\
& -17,280\left(P e_{m}^{2}+672\right) \\
& \left.\times\left(P e_{m}^{2}+105\right)^{2}\right] / 11,614,343,086,080,000
\end{aligned}
$$

The sign of this discriminant is shown in Fig. 3:

It can be observed in Fig. 3 that the equation has a single real root with two complex conjugate roots for $\Delta<0$ which corresponds to the highest values of $P e_{m}$. Three distinct real roots were obtained for $\Delta>0$ which corresponds to smaller values of $P e_{m}$ and higher or moderate values of $R a_{m}$. The multiple real root case was obtained for $\Delta=0$. It corresponds to the intersection of the plane $\Delta=0$ with the surface $\Delta=F\left(R a_{m}, P e_{m}\right)$.

- Case with one real roots and two complex conjugates roots

For $\Delta<0$, Eq. (31) has one real root and two complex conjugate roots defined as a function of $R a_{m}$ and $P e_{m}$.
Thus, the maximum value of $m$ which is a function of $R a_{m}$ can then be calculated. The results are: $m= \pm \sqrt{ } 42 / 15 \cong \pm 0.432$ for $P e_{m}= \pm \sqrt{42}, R a_{m}=540$.

For a cavity heated from below $m_{\max }=\sqrt{ } 42 / 15$ was obtained for $P e_{m}=\sqrt{42}$ and $R a_{m}=540$. However, a stability analysis was needed to determine the range of $R a_{m}$ values, where the unicellular flow can occur. The value of $m$ can be seen as a function of the mass Rayleigh number in Fig. 5 for the cases, $P e_{m}=0, P e_{m}=6.5$, and $P e_{m}=10$. The solid line represents the case where no velocity is applied at the upper wall.

For $P e_{m}=0$, the species separation is only possible for a cell heated from below and when the Rayleigh number exceeds a critical value $R a_{m}>R a_{m_{\text {uni }}}(\psi>0)$.

A maximum separation is observed for an optimal value of Rayleigh number, where optimal coupling between convection and thermodiffusion time is achieved. When the mass Rayleigh number is lower than its optimal value, the thermodiffusion is predominant. In this case the separation, due mainly to thermodiffusion, is small. Conversely, when $R a_{m}>R a_{m_{\mathrm{opt}}}$, the convection regime increases and tends to reduce the species separation.

The dotted and dashed curves represent the case where a constant velocity is applied at the upper wall $\left(P e_{m}=6.5, P e_{m}=10\right)$. For this case $\left(P e_{m} \neq 0\right)$ the separation is always possible whether the

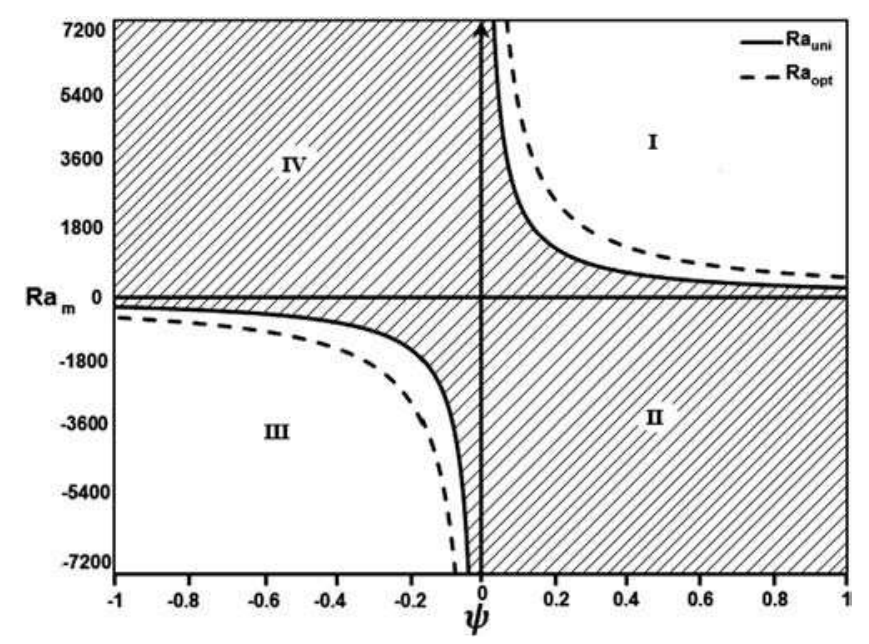

Fig. 2. Rayleigh number associated to the onset of monocellular flow and optimal separation versus $\psi$, for $P e=0$ and $L e=100$. 


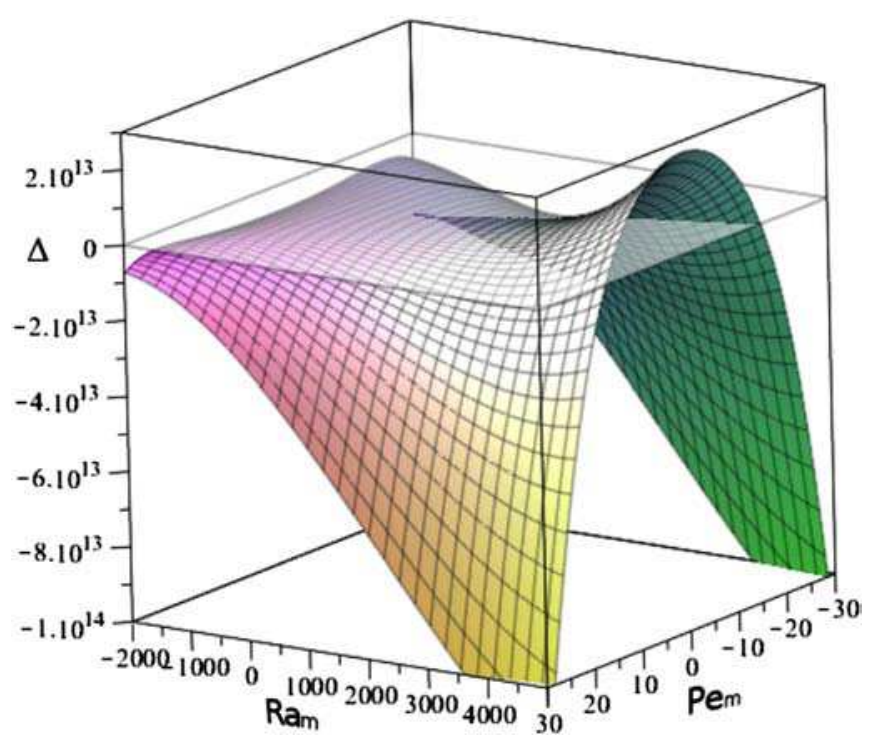

Fig. 3. 3D representation of the discriminant of Eq. (31).

layer is heated from above or from below. It can be explained by the fact that the temperature gradient induces thermodiffusion between the cold and the hot wall, and the applied velocity leads to species separation between the two ends of the horizontal cell.

For $P e_{m}=6.5$ and $P e_{m}=10$ the maximal value of $m$ is respectively $m=0.432$ obtained for $R a_{m}=537.5$ and $m=0.428$ obtained for $R a_{m}=100$. For $P e_{m}=0$ the maximum mass fraction gradient, $m=0.42$, is obtained for $R a_{m}=1200$ (heated from below).

A comparison of the specie separation variation $(S=m A)$ versus mass Péclet number $P e_{m}$ obtained, numerically and analytically, for a cell heated from below, $R a_{m}=537.5,(L e=100, \psi=0.1)$ is presented in Fig. 6 . The analytical solution is represented by solid lines and the numerical values are represented with dots. The analytical solution is in good agreement with the numerical results. When the mass Péclet number is small or large (i.e. the applied velocity is low or high), the ratio between the mass diffusion time and the convective time does not allow maximal species

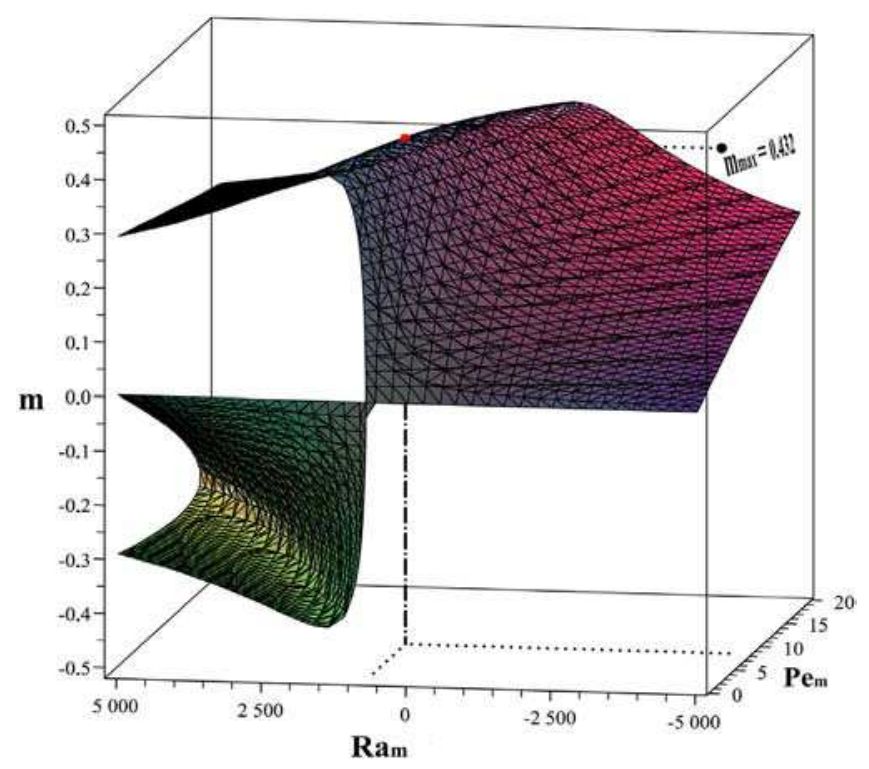

Fig. 4. 3D implicit surface associated to the Eq. (31).

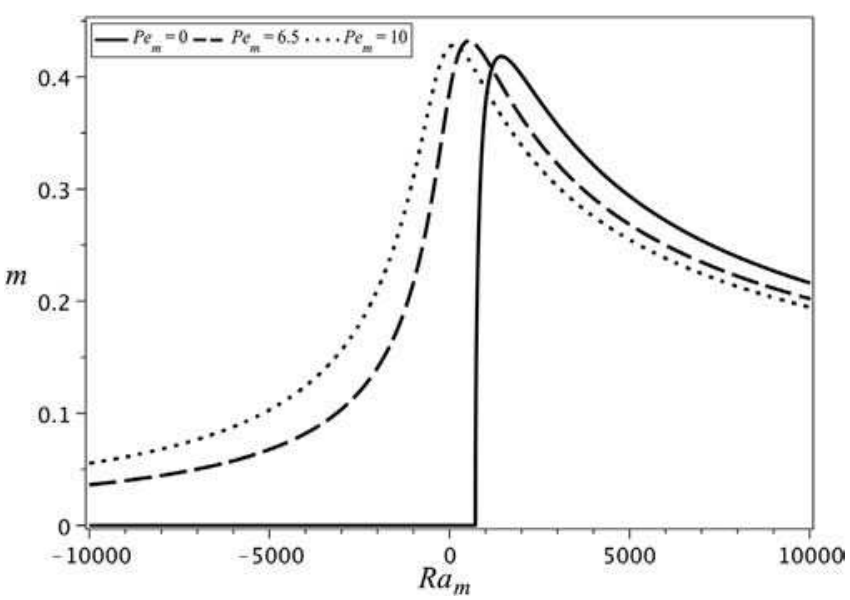

Fig. 5. Mass concentration gradient versus mass Rayleigh number for $P e_{m}=0$, $P e_{m}=6.5$ and $P e_{m}=10$ (Le $=100, \psi=0.1$ for example).

separation. This maximal value is equal to: $S=4.32$, obtained for $P e_{m}=6.5$ and $R a_{m}=537.5$ ( Le $=100, \psi=0.1$ ) (Table 1).

Fig. 7 gives an example of the variation of the mass fraction gradient field for different values of mass Péclet number $\left(P e_{m}\right)$, with $R a_{m}=537.5,(L e=100, \psi=0.1, P r=10)$ and $A=10$. The black lines represent the iso-mass fractions, while the colors represent the intensity of the mass fraction of the heaviest component.

When $\mathrm{Pe}_{m}$ increases, i.e. the velocity of flow increases, the isoconcentration curvature increases and the separation decreases.

In Fig. 8, a comparison of the specie separation, $S$, versus mass Péclet number for $R a_{m}=-400(L e=100, \psi=0.1$, $\operatorname{Pr}=10$ ) and $A=10$ is presented. It can be noted that the analytical results agree with the numerical ones. The maximum specie separation, $S=4.16$, is obtained for $P e_{m}=13$.

The iso-mass fractions, and the mass fraction fields are presented on Fig. 9 for $P e_{m}=10, P e_{m}=25$ with $R a_{m}=-400(L e=100, \psi=0.1, \operatorname{Pr}=10)$ and $A=10$.

- Case of three real roots, two of them are opposite.

From Eq. (31) we deduced the condition to obtain three real roots, two of which are opposite, by identifying its coefficients to those of the following equation $\left(m-m_{1}\right)\left(m^{2}-m_{2}^{2}\right)=0$ :

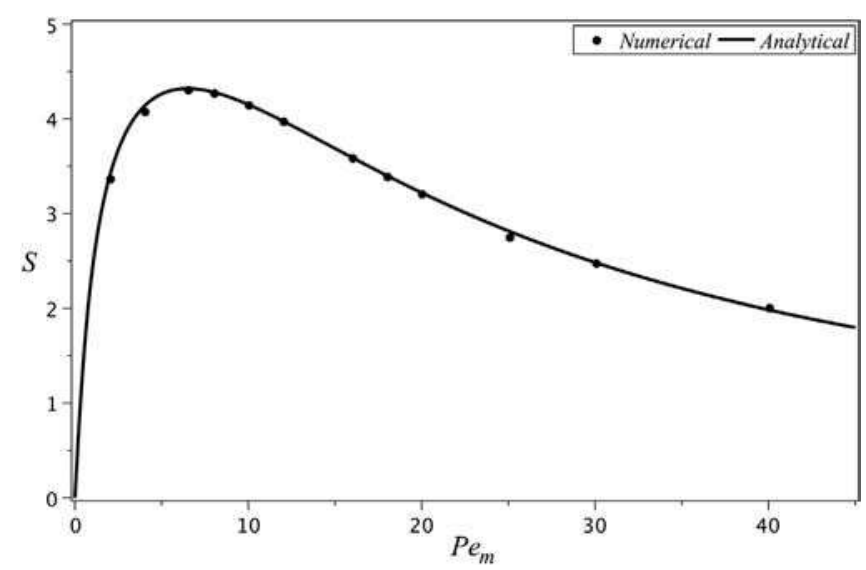

Fig. 6. Variation of separation $(S)$ versus mass Péclet number $\left(P e_{m}\right)$, for $R a_{m}=537.5$ $(L e=100, \psi=0.1, \operatorname{Pr}=10)$ and $A=10$. 
Table 1

Comparison between analytical and numerical results for $R a_{m}=537.5(L e=100, \psi=0.1)$ and $P r=10$.

\begin{tabular}{lll}
\hline$P e_{m}$ & $S_{\text {Ana }}$ & $S_{\text {Num }}$ \\
\hline 2 & 3.40 & 3.37 \\
4 & 4.13 & 4.09 \\
6.5 & 4.32 & 4.31 \\
8 & 4.28 & 4.28 \\
10 & 4.15 & 4.15 \\
12 & 3.97 & 3.98 \\
14 & 3.78 & 3.77 \\
16 & 3.59 & 3.59 \\
18 & 3.40 & 3.40 \\
20 & 3.22 & 3.22 \\
25 & 2.78 & 2.76 \\
30 & 2.48 & 2.48 \\
40 & 2.00 & 2.01 \\
50 & 1.64 & 1.64 \\
\hline
\end{tabular}

$7 R a_{m}-108 P e_{m}^{2}-11,340=0$

Eq. (35) shows that the mass Rayleigh number is always positive. Using this condition we obtain the three real roots:

$m_{1}=-\frac{108 P e_{m}}{R a_{m}}=-\frac{7 P e_{m}}{P e_{m}^{2}+105}$

$m_{2,3}= \pm 6 \sqrt{-\frac{10,080}{R a_{m}^{2}}+\frac{14}{R a_{m}}-\frac{P e_{m}^{2}}{R a_{m}^{2}}}= \pm \frac{7}{9} \sqrt{\frac{30}{P e_{m}^{2}+105}}$

It can be deduced from Eqs. (36) and (37) that the maximal value of the mass fraction gradient is $m_{1 \max }=-\sqrt{105} / 30 \approx-0.342$ and the associated values are $m_{2,3}= \pm \sqrt{7} / 9 \cong \pm 0.294$ obtained for $P e_{m, \text { opt }}= \pm \sqrt{105}$ and $m_{2.3 \max }= \pm \sqrt{14} / 9 \approx \pm 0.416$, obtained for $P e_{m}=0$. These two values $m_{2,3}$ max are located at the intersection of the $m$-axis and the 3D implicit surface associated to Eq. (31) presented in Fig. 4.

The evolutions of the three real roots of Eq. (31) are plotted versus mass Péclet number $P e_{m}$ in Fig. 10.

The two symmetrical curves represent the mass fraction gradient, $m$, obtained using Eq. (37) while the dotted line shows the mass fraction gradient, $m_{1}$, obtained using Eq. (36). In this case, the mass fraction gradient is equal to zero for $\mathrm{Pe}_{m}=0$ independently of the value of $R a_{m}$.

For $P e_{m}=0$ and $R a_{m}=1620$, there are 3 real roots, two of which are non-zero:

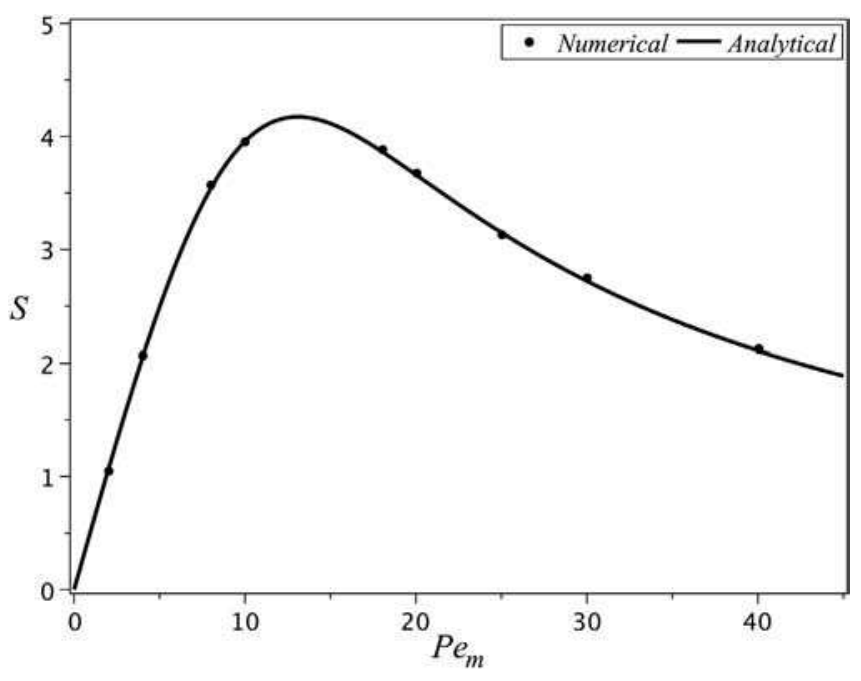

Fig. 8. Variation of separation $(S)$ versus mass Péclet number $\left(P e_{m}\right)$, for $R a_{m}=-400$ $(L e=100, \psi=0.1, \operatorname{Pr}=10)$ and $A=10$.

$m_{2,3}= \pm \sqrt{ } 14 / 9$ which correspond to a clockwise and a counterclockwise unicellular convective flow. All three corresponding velocity fields are represented in Fig. 11

As shown in Fig. 12, for $P e_{m}>0$, the two flows associated to the two opposite roots $m_{2,3}$ are completely different to the unicellular free convective flow obtained for $P e_{m}=0$. The flow induced by the movement of the upper wall, increased by the natural convective flow, rotating clockwise is associated to $m_{3}=-(7 / 9)$ $\sqrt{30 /\left(P e_{m}^{2}+105\right)}$ and the flow presenting two counter-rotating superposed cells corresponds to $m_{2}=(7 / 9) \sqrt{30 /\left(P e_{m}^{2}+105\right)}$. The third real root, $m_{1}$ is also associated to a convective flow presenting two counter-rotating superposed cells. The flow is obtained when the convective roll is counter-clockwise. The corresponding velocity profile is presented using dashed line in Fig. 12, for $P e_{m}=10, L e=100$. In this case, a large amount of the fluid located in the upper part of the cavity moves in the direction opposite to the upper wall movement leading to a negative value of $m$.

- Case of three real roots, two of them are equal.

By identifying the coefficients of the equation $\left(m-m_{1}\right)\left(m-m_{2}\right)^{2}=0$ to those of the cubic Eq. (31), we deduced

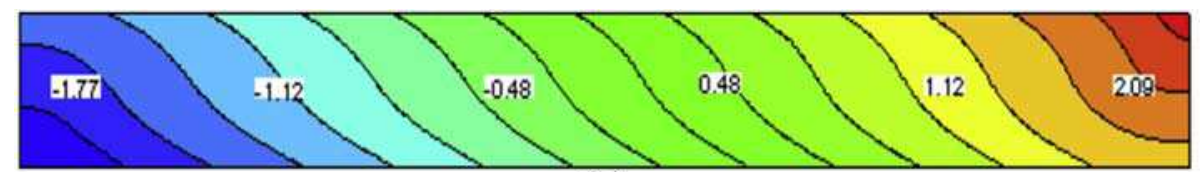

(a)

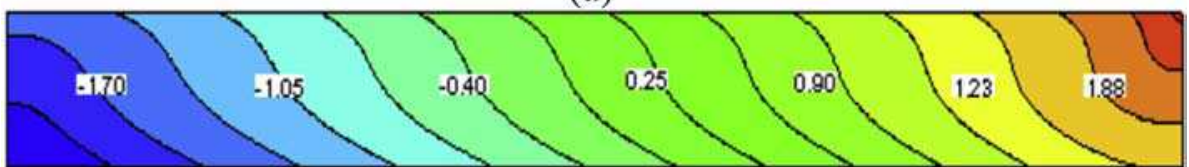

(b)

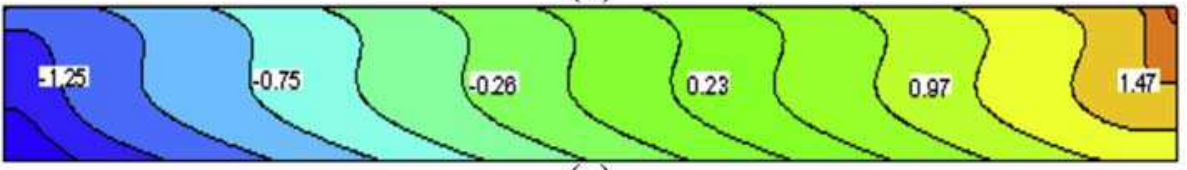

(c)

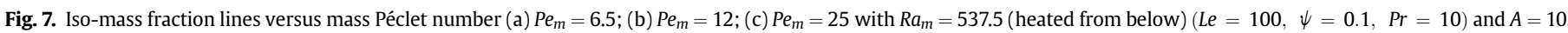




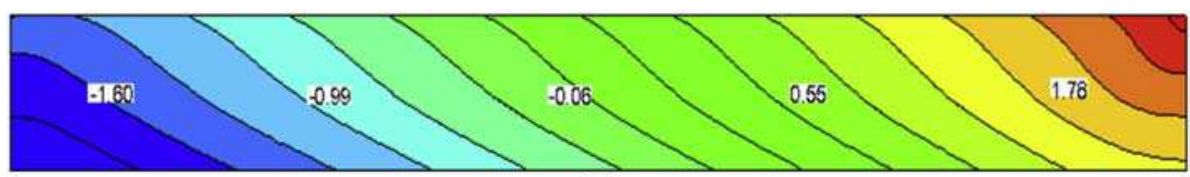

(a)

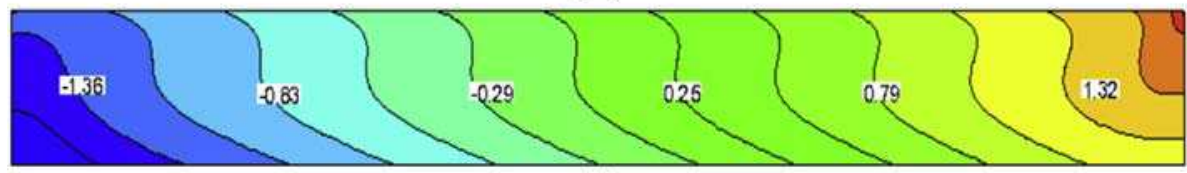

(b)

Fig. 9. Iso-mass fraction lines versus mass Péclet number (a) $P e_{m}=10$; (b) $P e_{m}=25$, for $R a_{m}=-400$ (heated from above) (Le $\left.=100, \psi=0.1, P r=10\right)$ and $A=10$.

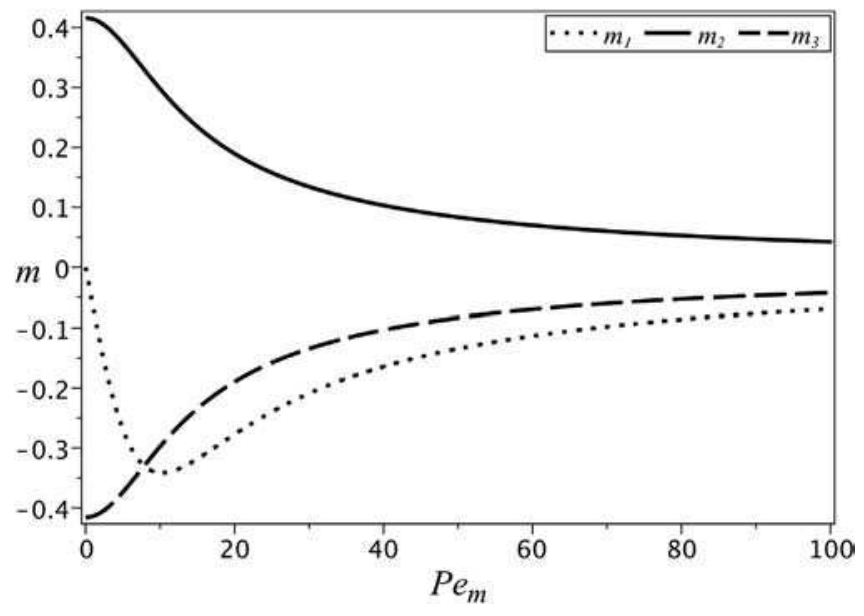

Fig. 10. Mass fraction gradient, $m$, versus mass Péclet number (case of three real roots with two opposite).

the relation coupling $P e_{m}$ and $R a_{m}$, leading to the case where two negative roots are equal and the third one positive :

$$
\begin{aligned}
& P e_{m}\left(324 P e_{m}^{2}+126 R a_{m}+136,080\right) \\
& -\sqrt{6}\left(6 P e_{m}^{2}+7 R a_{m}-5040\right)^{\frac{3}{2}}=0
\end{aligned}
$$

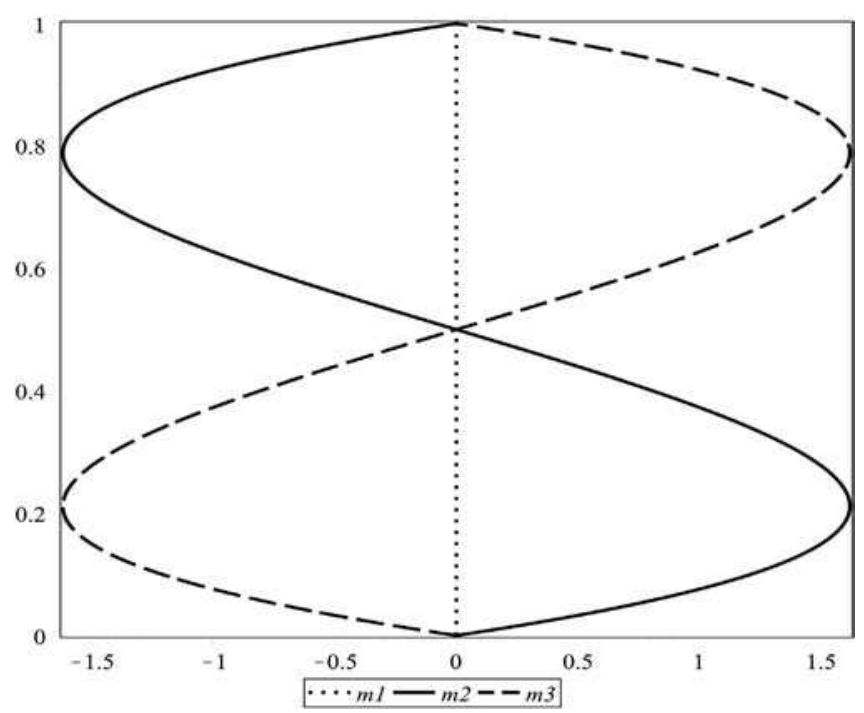

Fig. 11. Velocity profile associated to concentration gradient, $m_{1}=0$ (dotted line), and $m_{2,3}= \pm(\sqrt{14} / 9)$ for $R a_{m}=1620$ and $P e_{m}=0$.
The corresponding three real roots were obtained using condition (38):

$m_{1}=4 \frac{\left(-9 P e_{m}+\sqrt{36 P e_{m}^{2}+42 R a_{m}-30,240}\right)}{R a_{m}}$

$m_{2,3}=-2 \frac{18 P e_{m}+\sqrt{36 P e_{m}^{2}+42 R a_{m}-30,240}}{R a_{m}}$

Solving the cubic Eq. (38) with respect to $R a_{m}$, leads to one real root and two conjugate complex roots, thus, $R a_{m}$ can be expressed as a function of $\mathrm{Pe}_{m}$ :

$R a_{m}=720-\frac{6}{7} P e_{m}^{2}+\frac{1}{7}\left(N+\frac{P e_{m}^{2}}{N}+P e_{m}\right)^{2}$

With:

$$
\begin{aligned}
N= & \left(4 P e_{m}^{3}+3150 P e_{m}\right. \\
& \left.+\sqrt{15 P e_{m}^{6}+25200 P e_{m}^{4}+9,922,500 P e_{m}^{2}}\right)^{1 / 3}
\end{aligned}
$$

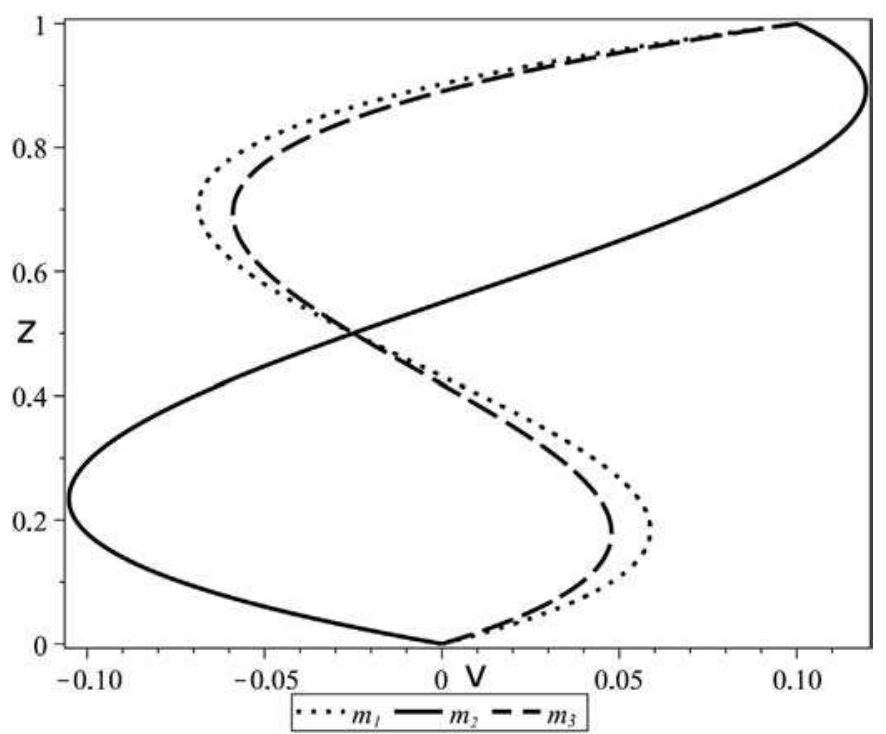

Fig. 12. Velocity profile associated to concentration gradient, $m_{1}, m_{2}$ and $m_{3}$ for $R a_{m}=$ $108\left(P e_{m}^{2}+105\right) / 7$ and $P e_{m}=10$ and $L e=100$. 


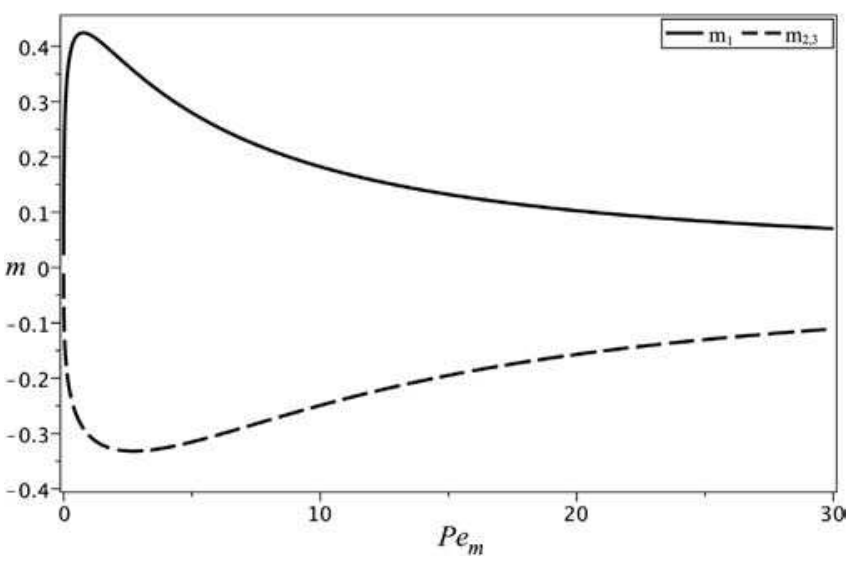

Fig 13. Mass fraction gradient, $m$, versus mass Péclet number (case with three real roots, two of which are equal and negative), for $L e=230, \psi=0.2$.

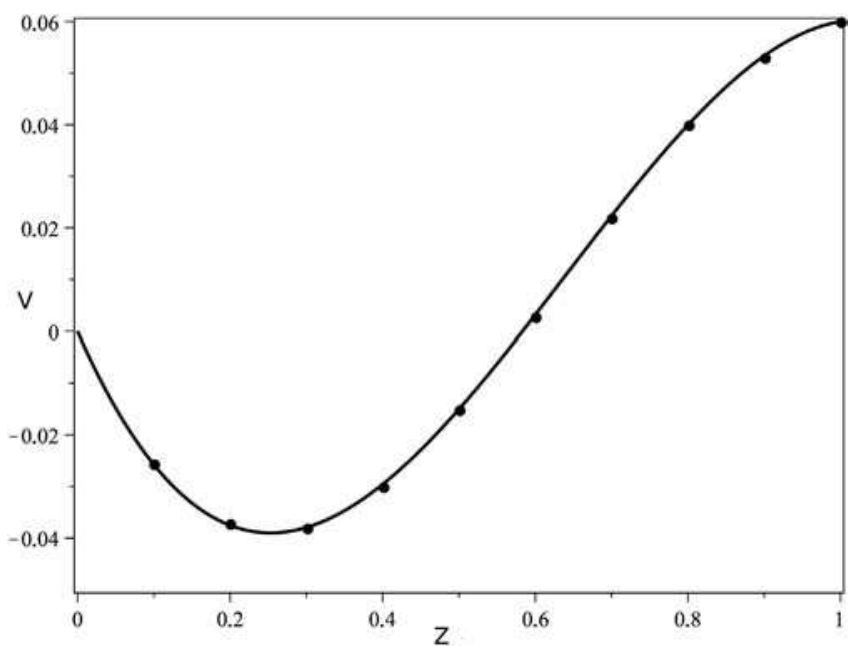

Fig. 14. Velocity profile for $R a=60, L e=100, \psi=0.1, P e=0.06$, and $A=10$.

We verified that $m_{1}$ and $m_{2,3}$ are only function of $P e_{m}$, using Eq. (41).

The evolutions of these three real roots are plotted versus mass Péclet number in Fig 13:

The maximum separation is observed, in Fig 13, for an optimal value of mass Péclet number, for which optimal coupling between forced convection and thermodiffusion time is achieved. When the value of $\mathrm{Pe}_{m}$ is lower than the optimal value, the thermodiffusion is predominant. In this case the separation, due mainly to thermodiffusion, is small.

Conversely, when $P e_{m}>P e_{m o p t}$, the convection regime increases and tends to reduce the species separation.

\subsection{Determination of $m$ for the particular case $R a_{m} \rightarrow 0$}

For $R a_{m} \rightarrow 0$ (corresponding to the case $\Delta T$ or $H \rightarrow 0$ ), Eq. (31) has a single root given by:

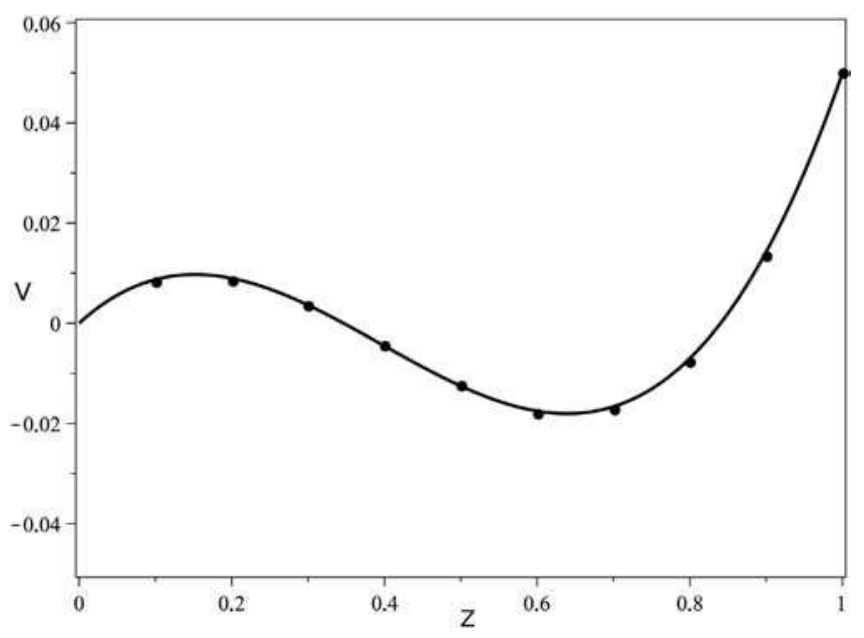

Fig. 16. Velocity profile of for $R a=200, L e=100, \psi=0.1, P e=0.05$, and $A=10$.

$m\left(R a_{m}=0\right)=\frac{35}{4}\left(\frac{P e_{m}}{P e_{m}^{2}+105}\right)$

The maximal value of the mass fraction gradient is obtained for $P e_{m, \text { opt }}= \pm \sqrt{105}$ and corresponds to: $m_{\max }\left(R a_{m}=0, P e_{m}=\right.$ $\left.P e_{m, \text { opt }}\right)=\sqrt{105} / 24 \cong 0.427$.

\section{Influence of velocity profile on the separation}

The structure of the flow inside the cavity and the associated velocity profile induced by the top wall driven at constant velocity along the $x$ axis depends on the direction of the convective rotating vortex generated by free convection inside the horizontal cell.

The equation of the velocity profile obtained in Eq. (26) can be also written in the form:

$u=\frac{1}{12} z\left[\left(-2 z^{2}+3 z-1\right) R a \psi m+(36 z-24) P e\right]$

We verify that the value of the discriminant of the quadratic equation associated with the velocity is positive for all values of $R a$, $\mathrm{Pe}$ and $\psi$. Thus there are two distinct real roots. If these two roots are in the interval ] 0,1 [ the velocity is equal zero at two points inside the cross section of the cell. We show that both roots are located in the interval $] 0,1$ [ only when the value of $X=P e / R a \psi m$ is in the range of ] $-0.042,0$ [. The velocity profile in the cavity for $R a=$ $60, \psi=0.1, P e=0.06, m=0.4319$ and $A=10$ leads to $X=0.0231 \notin[-0.042,0]$. It then follows that the velocity profile has only one value of $z \in] 0,1$ [ for which the velocity equals zero. The corresponding velocity profile is presented in Fig. 14. The analytical solution is represented by solid line. The numerical values obtained for cross-section $x=5$ are represented with dots. In Fig. 15, the variation of the mass fraction field obtained numerically with same values of $(P e, R a, L e, \psi, A, m)$ is presented. The color indicates the intensity of the mass fraction of the heaviest species. The lines represent the associated stream function and the arrows indicate the direction of the flow.

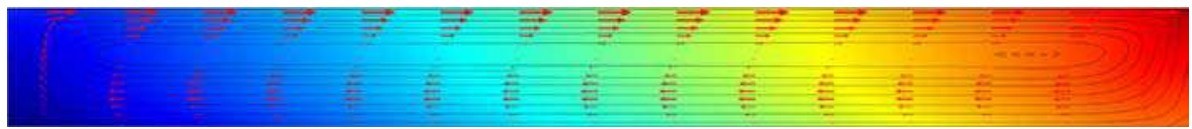

Fig. 15. Variation of the mass fraction field and streamlines for $R a=60, L e=100, \psi=0.1, P e=0.06$ and $A=10$. 


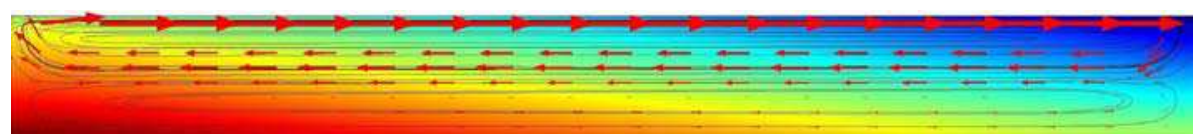

Fig. 17. Variation of the mass fraction field and streamlines for $R a=200, L e=100, \psi=0.1, P e=0.05$ and $A=10$.

For $R a=200, \psi=0.1, P e=0.05$, and $A=10$, leading to $m=-0.1436$, the value of $X=-0.0174$ is in the range of $]-0.042,0$ and the velocity is zero for two values of $z\left(z_{1}=0.35, z_{2}=0.84\right.$ $\in] 0,1[$. The corresponding velocity profile is shown in Fig. 16. The analytical solution is represented by solid line and numerical values obtained for cross-section $x=5$ are represented with dots. The results between analytical and numerical values are in very good agreement.

Fig. 17 illustrates the variation of the mass concentration field obtained numerically with $P e=0.05, R a=200, L e=100, \psi=0.1$, $A=10$. The colored scale represents the intensity of the mass fraction of the heaviest component. The lines represent the associated stream function and the arrows show the direction of the flow.

In the latter case, associated to two convective cells, the corresponding species stratification is different from the stratification obtained in the single convective cell case. The mass concentration gradient $m$ decreases contrary to the case with a single convective cell.

\section{Conclusion}

In this work, a new procedure leading to species separation in a horizontal rectangular cavity filled with a binary fluid, heated from above or from below, has been studied. A constant horizontal velocity was applied to the upper horizontal wall. The two control parameters of this procedure were the applied velocity on the upper wall, which determines the intensity of the forced convective flow, and the temperature difference between the two horizontal plates, which controls the intensity of the thermodiffusion. In this study the species separation was quantified by both analytical and numerical methods. The influence of the thermal Rayleigh number and the Péclet number for different values of separation ratio, Prandlt and Lewis numbers on species separation was quantified and discussed. It was proved that the mass concentration gradient $m$ is only function of two new dimensionless parameters, $\psi R a$ Le $=$ $R a_{m}$ and $P e L e=P e_{m}$ while the general problem depends on five dimensionless parameters $(R a, P e, P r, L e, \psi)$. The optimal species separation was obtained for a cell heated from below or from above. The cases with $P e_{m}=0$ and $R a_{m} \rightarrow 0$ were also studied. The analytical and numerical results obtained were in good agreement.

\section{References}

[1] K. Clusius, G. Dickel, New process for separation of gas mixtures and isotopes, Naturwissenschaften 26 (1938) 546.

[2] W.H. Furry, R.C. Jones, L. Onsager, On the theory of isotope separation by thermal diffusion, Phys. Rev. 55 (1939) 1083-1095.

[3] M. Lorenz, A.H. Emery, The packed thermal diffusion column, Chem. Eng. Sci. 11 (1959) 16-23.

[4] M.M. Bou-Ali, O. Ecenarro, J.A. Madariaga, C.M. Santamaria, J.J. Valencia, Stability of convection in a vertical binary fluid layer with an adverse density gradient, Phys. Rev. E 59 (1999) 1250-1252.

[5] V.M. Shevtsova, D.E. Melnikov, J.C. Legros, Onset of convection in Soret-driven instability, Phys. Rev. E Stat. Nonlin. Soft Mat. Phys. 73 (2006) 047302.

[6] V. Shevtsova, D. Melnikov, J.C. Legros, Unstable density stratification in binary mixture, Progr. Comput. Fluid Dyn. 6 (2006) 348-356.

[7] J.K. Platten, M.M. Bou-Ali, J.F. Dutrieux, Enhanced molecular separation in inclined thermogravitational columns, J. Phys. Chem. B 107 (2003) 1176311767.

[8] B. Elhajjar, A. Mojtabi, M. Marcoux, M.C. Charrier-Mojtabi, Study of thermogravitation in a horizontal fluid layer, C. R. Mecanique 334 (2006) $621-627$.

[9] M.C. Charrier-Mojtabi, B. Elhajjar, A. Mojtabi, Analytical and numerical stability analysis of Soret-driven convection in a horizontal porous layer, Phys. Fluids 19 (2007) 124104.

[10] B. Elhajjar, M.C. Charrier-Mojtabi, A. Mojtabi, Separation of a binary fluid mixture in a porous horizontal cavity, Phys. Rev. E 77 (2008) 026310.

[11] R. Bennacer, A. Mahidjiba, P. Vasseur, H. Beji, R. Duval, The Soret effect on convection in a horizontal porous domain under cross temperature and concentration gradients, Int. J. Numer. Methods Heat Fluid Flow 13 (2003) 199-215.

[12] A. Zebib, M.M. Bou-Ali, Inclined layer Soret instabilities, Phys. Rev. E 79 (2009) 056305.

[13] B. Elhajjar, A. Mojtabi, M.C. Charrier-Mojtabi, Influence of vertical vibrations on the separation of a binary mixture in a horizontal porous layer heated from below, Int. J. Heat Mass Transfer 52 (2009) 165-172.

[14] Z. Alloui, L. Dufau, H. Beji, P. Vasseur, Multiple steady states in a porous enclosure partially heated and fully salted from below, Int. J. Thermal Sci. 48 (2009) 521-534.

[15] B. Elhajjar, A. Mojtabi, P. Costeseque, M.C. Charrier-Mojtabi, Separation in an inclined porous thermogravitational cell, Int. J. Heat Mass Transfer 53 (2010) 4844-4851.

[16] E. Knobloch, D.R. Moore, Linear stability of experimental Soret convection, Phys. Rev. A (1988) 860-870. 